\title{
Tandem-L: \\ A Highly Innovative Bistatic \\ SAR Mission for Clobal Observation \\ of Dynamic Processes \\ on the Earth's Surface
}

\section{ALBERTO MOREIRA, GERHARD KRIEGER, IRENA HAJNSEK*, KONSTANTINOS PAPATHANASSIOU, MARWAN YOUNIS, PACO LOPEZ-DEKKER, SIGURD HUBER, MICHELANGELO VILLANO, AND MATTEO PARDINI}

German Aerospace Center (DLR),

Microwaves and Radar Institute, Germany

(e-mail: alberto.moreira@dlr.de)

*Irena Hajnsek is also with ETH Zurich,

Institute of Environmental Engineering, Switzerland

(e-mail: irena.hajnsek@dlr.de)

\section{MICHAEL EINEDER, FRANCESCO DE ZAN, AND ALESSANDRO PARIZZI}

German Aerospace Center (DLR), Remote Sensing Technology Institute,

Germany (e-mail: michael.eineder@dlr.de)

Digital Object Identifier 10.1109/MGRS.2015:2437353 Date of publication: 30 July 2015 
Abstract-Tandem-L is a proposal for a highly innovative L-band SAR satellite mission for the global observation of dynamic processes on the Earth's surface with hitherto unparalleled quality and resolution. It is based on the results of a pre-phase A study which started in 2013 and is currently undergoing a phase-A study. Thanks to the novel imaging techniques and the vast recording capacity with up to 8 terabytes/day, it will provide vital information for solving pressing scientific questions in the biosphere, geosphere, cryosphere, and hydrosphere. By this, the new L-band SAR mission will make an essential contribution for a better understanding of the Earth system and its dynamics. Tandem-L will, moreover, open new opportunities for risk analysis, disaster management and environmental monitoring by employing especially designed acquisition modes and techniques in combination with a reconfigurable tandem satellite configuration and an L-band SAR instrument with advanced digital beamforming techniques.

\section{INTRODUCTION}

he Tandem-L mission concept is based on the use of two SAR satellites operating in L-band

(23.6 cm wavelength) with variable formation flight configurations and is distinguished by its high degree of innovation with respect to the methodology and technology [1], [2], [3]. Examples are the polarimetric SAR interferometry for measuring forest height, multi-pass coherence tomography for determining the vertical structure of vegetation and ice, the utilization of the latest digital beamforming techniques in combination with a large deployable reflector for increasing the swath width and imaging resolution, as well as the formation flying of two cooperative radar satellites with adjustable spacing for single-pass interferometry [5].

The mission proposal Tandem-L has been elaborated during a pre-phase-A study that lasted until August 2014 and is now being further developed in the scope of a phase-A study. The systematic acquisition concept is based on two imaging modes: 1) 3-D structure mode with a bistatic radar operation and 2) deformation imaging mode with differential SAR interferometry, both allowing the following mission objectives to be achieved:

Dlobal measurement of 3-D forest structure and biomass for a better understanding of ecosystem dynamics and the carbon cycle,

D systematic recording of deformations of the Earth's surface with millimeter accuracy for earthquake research and risk analysis,

D quantification of glacier movements and melting processes in the polar regions for improved predictions of sea level rise,

D high resolution measurement of variations in soil moisture close to the surface for advanced water cycle research,

Dystematic observation of coastal zones and sea ice for environmental monitoring and ship routing,

Dapping of agricultural fields for crop and rice yield forecasts,

Donitoring of infrastructure and its degradation, as well as disaster monitoring.

The current goal of Tandem-L is to interferometrically image large portions of the global landmass once a week. By extending the downlink capacity with a Laser Communication Terminal (LCT), it would even be possible to further increase the mapping capability and to monitor the entire landmass of the Earth twice every week. Above and beyond the primary mission goals, the unique data set acquired by Tandem-L has therefore immense potential for developing new scientific and commercial applications and services.

\section{SCIENCE AND USER REQUIREMENTS}

The motivation for the mission originates from the emerging scientific requirements to better understand and quantify dynamic processes within the Earth system at different spatial and temporal scales (see Figure 1), including their interdependency and interaction. Many of these processes are currently insufficiently understood and/or measured, primarily due to the lack of suitable observation data required. Existing remote sensing configurations are often inadequate in terms of imaging performance and/or measurement resolution and accuracy for drawing reliable conclusions on largescale processes and their dynamics [3], [5], [6], [7].

The measurement of dynamic processes requires a continuous, extended and systematically planned observation strategy in order to detect changes and quantify them with sufficient accuracy. Depending on the processes to be observed, changes have to be measured on variable spatial and temporal scales and then related to one another. The combination of short revisit times and extended acquisitions over several 


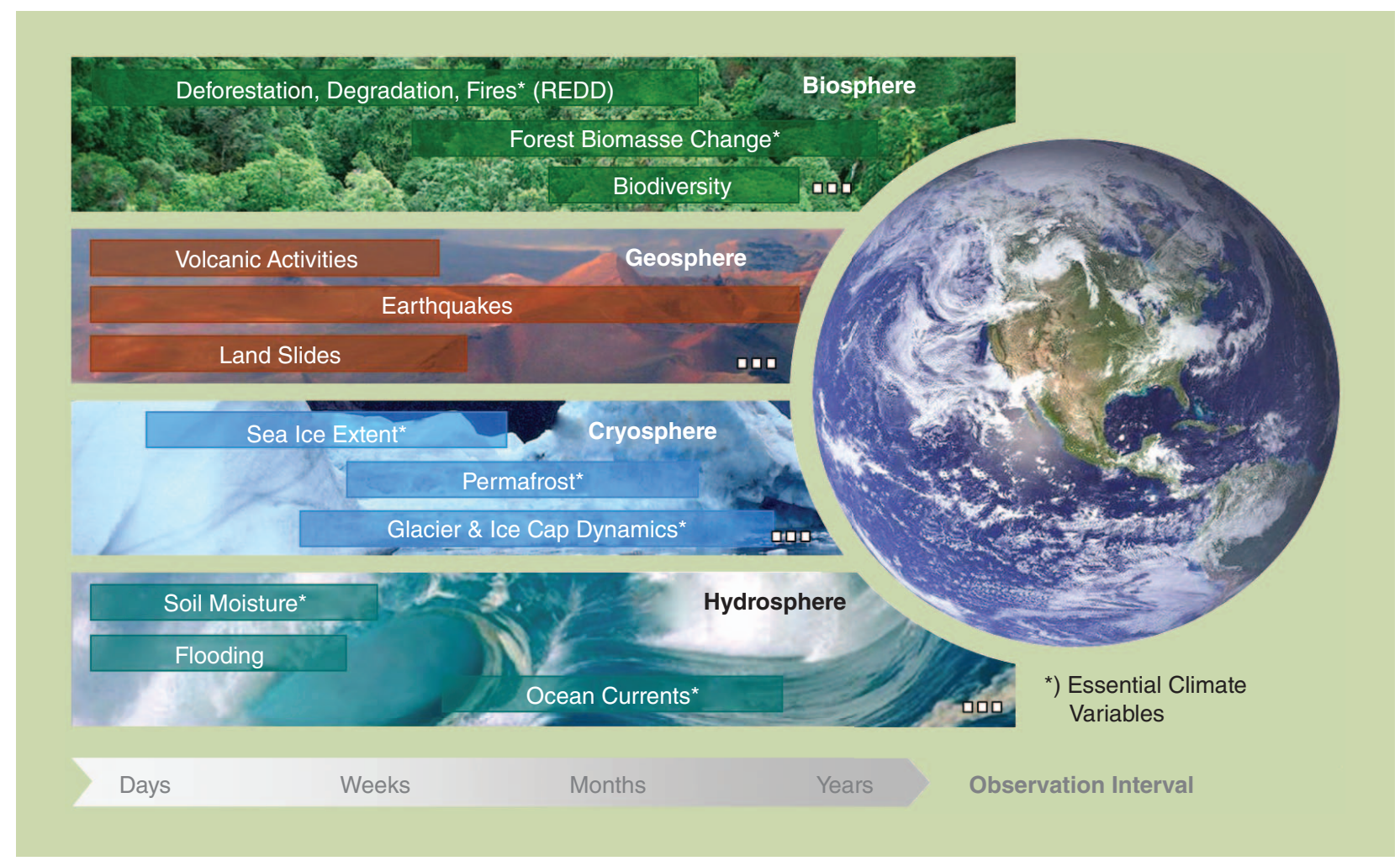

FIGURE 1. Examples of dynamic processes on the Earth's surface to be monitored by Tandem-L. By the use of digital beamforming techniques in elevation and azimuth in combination with a large deployable reflector, the stringent scientific and user requirements for global monitoring with high resolution and wide swath including polarimetric and interferometric imaging modes can be met.

years is required when it comes to monitor fast-occurring, highly-dynamic processes, such as the relaxation following an earthquake, as well as slowly-occurring processes, like the inter-annual variation of forest biomass, with the necessary accuracy and resolution. The fulfillment of these basic requirements defines the profile of the mission: Tandem- $\mathrm{L}$ should be able to image large areas regularly, in the shortest possible time intervals and with high spatial resolution over several years. This, together with a systematically planned acquisition strategy, should enable the generation of consistent time series for the entire Earth.

Parallel to the systematic mapping and monitoring of Earth system processes, Tandem-L should be able to serve emergency and disaster situations providing not only images with high spatial and temporal resolution, but also information products, as for example topographic information, terrain deformation and change and critical infrastructure mapping.

A number of science team meetings and user workshops organized in the last years by DLR have been used to define, consolidate and prioritize 10 application areas with the associated (Level-2 and 3) products as the mission driving science products:

1) Large scale deformation: Tandem- $L$ is the first configuration optimized for monitoring of terrain deformation without compromises. It has therefore the potential to be a milestone mission in mapping the highly dynamic changes of Earth's topography [8], [9], [10], [11]. Five different application scenarios are considered:
- Inter-seismic deformation: 3-D displacement vector maps with an accuracy of $2 \mathrm{~mm} /$ year at the end of the mission on a $50 \times 50 \mathrm{~m}^{2}$ grid for all critical areas (i.e., tectonic areas with a strain rate $>3 \times 10^{-9}$ /year - see also Figure 2).

- Co-seismic deformation: 3-D displacement vector maps with an accuracy of $10 \mathrm{~mm}$ (after Atmospheric Phase Screen (APS) removal) on a $10 \times 10 \mathrm{~m}^{2}$ grid.

- Tectonics for volcanoes: For 1538 holocene volcanoes worldwide 3-D displacement vector map with a $5 \mathrm{~mm}$ accuracy (after APS removal) on a $20 \times 20 \mathrm{~m}^{2}$ grid.

- Urban subsidence: Subsidence maps with an accuracy of $1 \mathrm{~mm} /$ year on a $20 \times 20 \mathrm{~m}^{2}$ grid for 754 cities worldwide. An example is shown in Figure 2 where the rapid subsidence of the city of Semarang and its surroundings is measured by ALOS/PalSAR.

- Landslides: 2-D velocity map with an accuracy of 5-10 mm (after APS removal) on a $10 \times 10 \mathrm{~m}^{2}$ grid. All applications take advantage of a DEM acquired in bistatic mode from the same wavelength and observation geometry as the deformation measurement.

2) Global base map: Coverage of all land surfaces in a 10-meter resolution twice a year in order to establish a consistent global archive of polarimetric bistatic interferometric data. The interferometric data acquired during the different mission phases will provide global digital elevation and terrain models (DEM and DTM) with a quality comparable to the final product being 
available by the TanDEM-X mission [32], [33].

3) Forests: Especially for forest applications Tandem-L has the potential to initialize a new era providing products that allows a systematic monitoring of natural and anthropogenic forest change processes:

- Forest structure: Global forest 3-D mapping with a voxel size of $10 \times 50 \times 50 \mathrm{~m}^{3}$ twice a year in order to monitor annual and seasonal forest structure changes. Tandem-L will allow for the first time ever to map the vertical forest structure and to monitor seasonal and annual variation globally with a high spatial resolution. This will enable to map for the first time the (vertical) complexity and diversity of Earth's forest ecosystems and to assess the extent and intensity of forest structural disturbances [13], [14].

- Forest height: Annual global forest height mapping with accuracy better than $10 \%$ on a $50 \times 50 \mathrm{~m}^{2}$ grid. An example of forest monitoring over a period of 10 years by means of forest height maps - of the same/ similar specification as the ones expected from Tandem- $\mathrm{L}$ - is shown in Figure 3.

- Forest biomass: Annual global (above ground) forest biomass mapping with accuracy better than 20\% (or better than $20 \mathrm{t} /$ ha for biomass levels below $100 \mathrm{t} / \mathrm{ha}$ ) on a $70 \times 70 \mathrm{~m}^{2}$ grid. Tandem-L will measure biomass and its seasonal and yearly variation with unprecedented accuracy and spatial resolution on a global scale. This is a key contribution to the uncertainties in the terrestrial components of the carbon cycle [12].

4) Wetlands are highly vulnerable critical habitats and play a critical role in regional green-house gas balance:

- Wetland inundation maps on a monthly to quarterly basis especially from coastal regions and major river basins with a spatial resolution $<10 \mathrm{~m}$.

- Annual pan-tropical mangrove extent with a spatial resolution $<10 \mathrm{~m}$.

5) Agriculture maps (pasture):

- Mapping of (all) paddy rice fields with an accuracy $>30 \%$ and a $3 \mathrm{~m}$ spatial resolution every 16 days during the growth period.

- All remaining agricultural areas globally with a 10 m spatial resolution every 8 days for deriving crop calendars (aimed with an accuracy of 10 days on an annual basis) and crop classification maps with an accuracy $>60 \%$.

6) Soil moisture for defined hydrologically relevant sites/ areas:

- Mapping of the spatial variability of soil moisture with an accuracy of the order of $10 \%$ on a $50 \times 50 \mathrm{~m}^{2}$ grid with the highest possible temporal resolution (1-4 days). An example derived from data acquired by DLR's airborne E-SAR is shown in the lower left panel of Figure 4.

- Monitoring changes in soil moisture on a $50 \times$ $50 \mathrm{~m}^{2}$ grid. Tandem- $\mathrm{L}$ will provide for the first time soil moisture measurements over large areas with a spatial resolution appropriate to monitor spatial and temporal patterns of soil moisture at local scales and to develop methods and products for the support of future dedicated monitoring configurations [15], [16], [17].

7) Land ice and permafrost areas are both key components of the cryosphere. By measuring ice motion and ice topography, Tandem-L will deliver critical information for estimating ice mass balance. At the same time by mapping the (near surface) permafrost extent, Tandem-L will provide information crucial for better understanding dynamics and hydrology in the Arctic [18], [19], [20].

- Glacier velocity globally with an accuracy of 10 $20 \%$ on a spatial resolution of $10 \times 10 \mathrm{~m}^{2}\left(3 \times 3 \mathrm{~m}^{2}\right.$ for fast moving glaciers) on a weekly basis.

- Ice structure: Global ice 3-D mapping with a voxel size of $10 \times 100 \times 100 \mathrm{~m}^{3}$ on a seasonal basis. An example of vertical transect across the Austfonna ice cap in Svalbard revealing the firn and ice layers derived using tomographic techniques from data acquired along five tracks by DLR's airborne E-SAR is shown in Figure 5. 


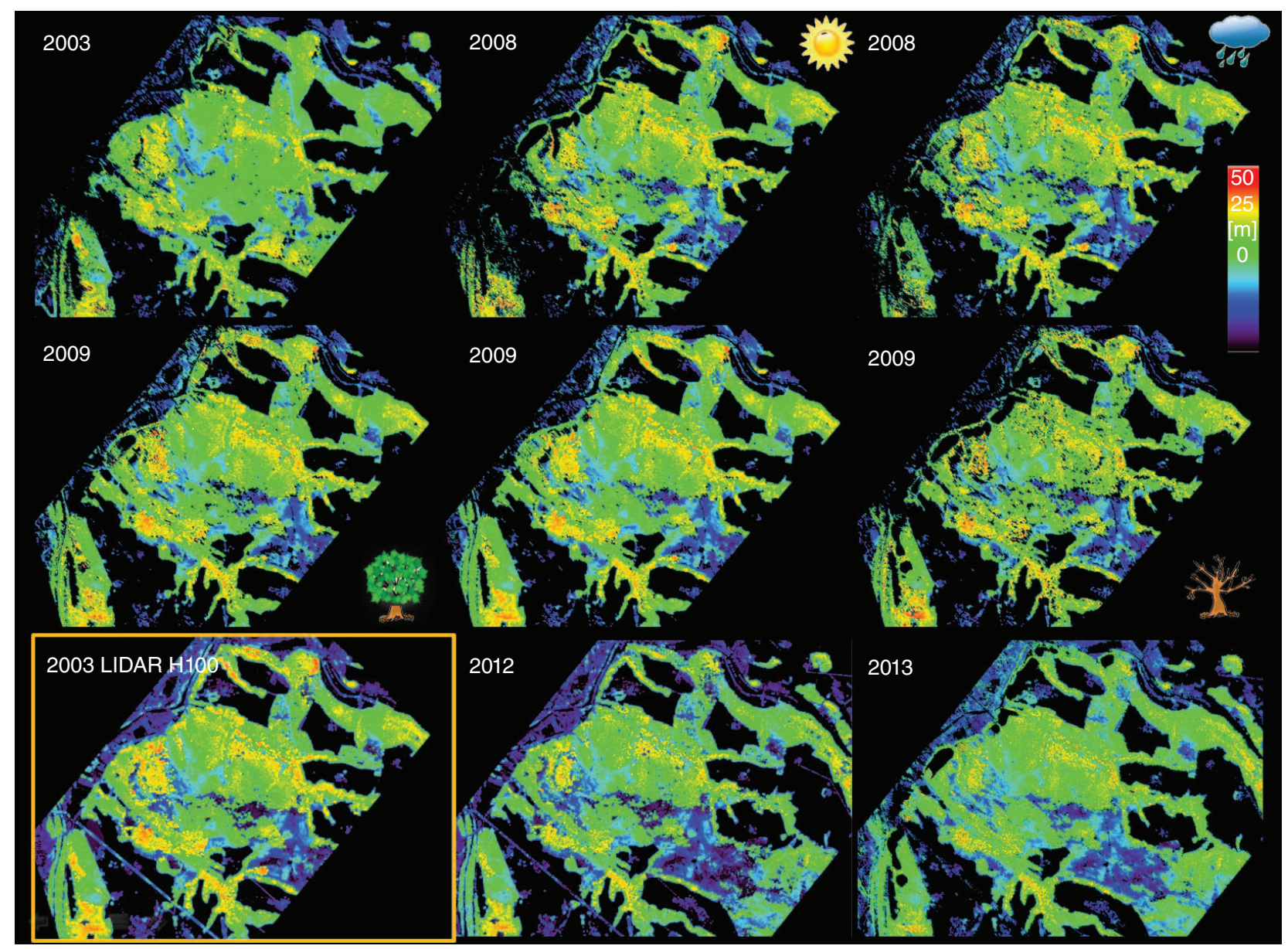

FIGURE 3. Forest height maps derived from model-based inversion of polarimetric SAR interferometric (Pol-InSAR) data acquired by DLR's airborne SAR system over the Traunstein forest located in Germany from 2003-2013 [36]. In 2008 the acquisitions where performed during wet (rain) and dry conditions (indicated by the cloud and sun pictogram) and in 2009 in leaves-on and leaves-off conditions (indicated by the leaves-on and leaves-off pictogram) - in all cases leading practically to the same height estimates. The reference map (for 2003) derived by airborne lidar data is shown in the lower left corner.

- Ice sheet elevation change globally with an accuracy of $10 \%$ on a spatial resolution of $50 \times 50 \mathrm{~m}^{2}$ on a seasonal basis.

- Grounding line position on the surroundings of Antarctica with an accuracy of $30 \mathrm{~m}$ on a spatial resolution of $30 \times 30 \mathrm{~m}^{2}$ on an annual (seasonal) basis.

- Permafrost extent globally with an accuracy of $10 \%$ on a spatial resolution of $10 \times 10 \mathrm{~m}^{2}$ on a seasonal basis.

8) Sea ice extent and type are both important components when it comes to estimate ice mass balance:

- Sea ice extent on Arctic and Antarctic oceans with $10 \%$ accuracy and spatial resolution of $10 \times 10 \mathrm{~m}^{2}$ to $50 \times 50 \mathrm{~m}^{2}$ on a seasonal basis.

- Sea ice type classification on Arctic and Antarctic oceans with $30 \%$ classification accuracy and spatial resolution of $10 \times 10 \mathrm{~m}^{2}$ to $50 \times 50 \mathrm{~m}^{2}$ on a seasonal basis.

9) Ocean Monitoring: Tandem-L will demonstrate a number of new products for ocean monitoring and at the same time allow the development of a new generation of methodology and applications:

- Ocean currents: On selected areas with an accuracy of $0.1 \mathrm{~m} / \mathrm{s}$ with a spatial resolution of $100 \times 100 \mathrm{~m}^{2}$ on a weekly basis.

- Wind speed velocity: Globally across a $200 \mathrm{~km}$ wide swath starting from the coast (from land) with an accuracy on the order of $1.5 \mathrm{~m} / \mathrm{s}$ on a spatial resolution of $100 \times 100 \mathrm{~m}^{2}$ at every opportunity.

- Coastal area change: Globally with a spatial resolution of $10 \times 10 \mathrm{~m}^{2}$ on an annual basis.

- Water level change: Regional with an accuracy of $10 \mathrm{~cm}$ and a spatial resolution of $50 \times 50 \mathrm{~m}^{2}$ on an annual basis.

10) Emergency mode: High resolution mode (3 m) for monitoring critical areas and infrastructure after a major event (including flooding, fire, landslides, volcanic and tectonic events).

The Tandem-L mission will make unique contributions to environmental and climate research by providing 
measurements of 7 essential climate variables (ECV). It will provide data and products able to support UNFCCC and IPCC activities. Tandem-L will pioneer in developing methods and products for the support of future monitoring systems for the implementation and verification of environmental policies.

The areas of interest - reflecting the spatial coverage requirements - for different key application areas/products are shown in Figure 6.

Recapitulating, the main mission requirements across all thematic topics and applications can be summarized as follows:

Dystematic and global coverage of the Earth's landmass with high temporal and spatial resolution;

D Combination of multiple imaging techniques to monitor processes in the various Earth spheres;

- Polarimetric SAR interferometry for a model-based retrieval of environmental parameters;

D Differential SAR interferometry to measure two-dimensional deformations on the land surface with millimeter accuracy;

D Minimization of temporal decorrelation induced errors by selection of appropriate frequency band and single-pass interferometry;

D Frequent global acquisitions, to systematically observe both slow and fast changes of bio- and geophysical parameters.

\section{MISSION CONCEPT}

\section{A. MEASUREMENT MODES}

The Tandem-L mission concept relies on a systematic data acquisition strategy using a pair of co-operating L-band SAR satellites flying in close formation. The satellite system will be operated in the following basic measurement modes:

D The 3-D structure mode is especially designed for the three-dimensional surveying and tomographic imaging of volume scatterers, such as vegetation, ice, snow and dry soil. This mode uses both satellites to collect fully polarimetric and interferometric SAR data with adjustable cross-track baselines (Figure 7, left). Thanks to the simultaneous data acquisition with two satellites, errors from temporal decorrelation and atmospheric disturbances can be minimized. This enables the

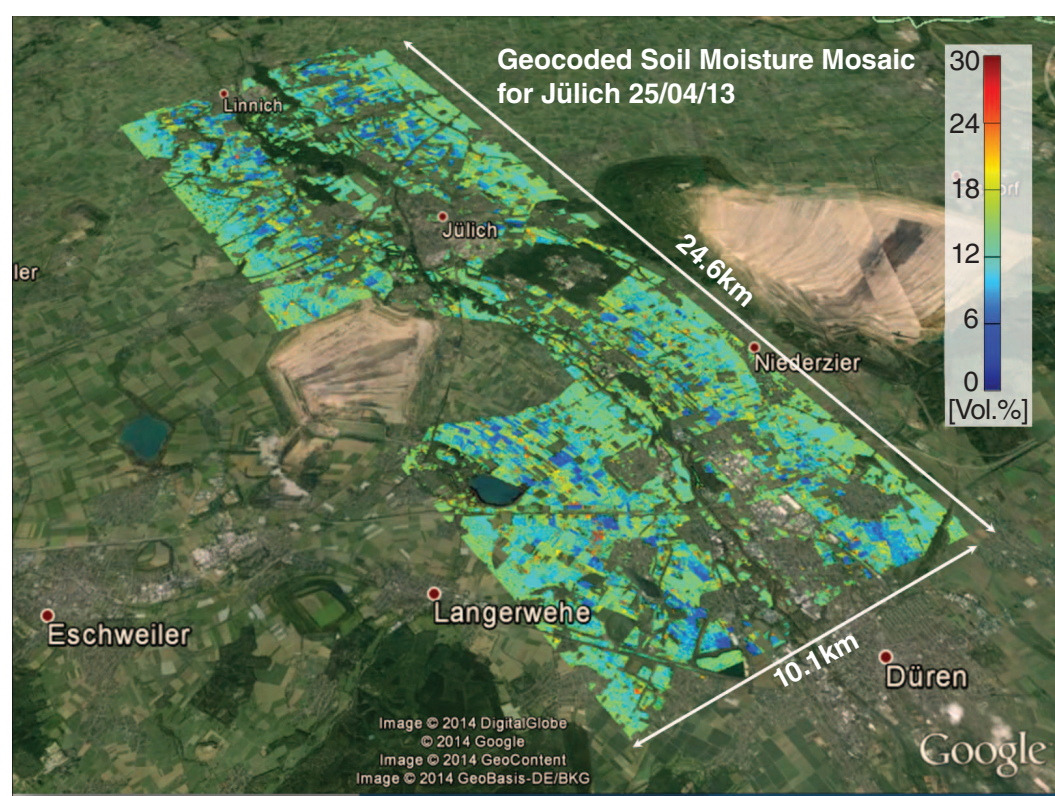

FIGURE 4. Wide-area soil moisture retrieval using F-SAR data at the TERENO Eifel observatory. A region of $10 \times 25 \mathrm{~km}^{2}$ has been exemplarily mapped, showing the potential as a spatially distributed input for hydrological or environmental models. Soil Moisture map of the Ruhr Catchment, Germany (excluding Cities and Forest).

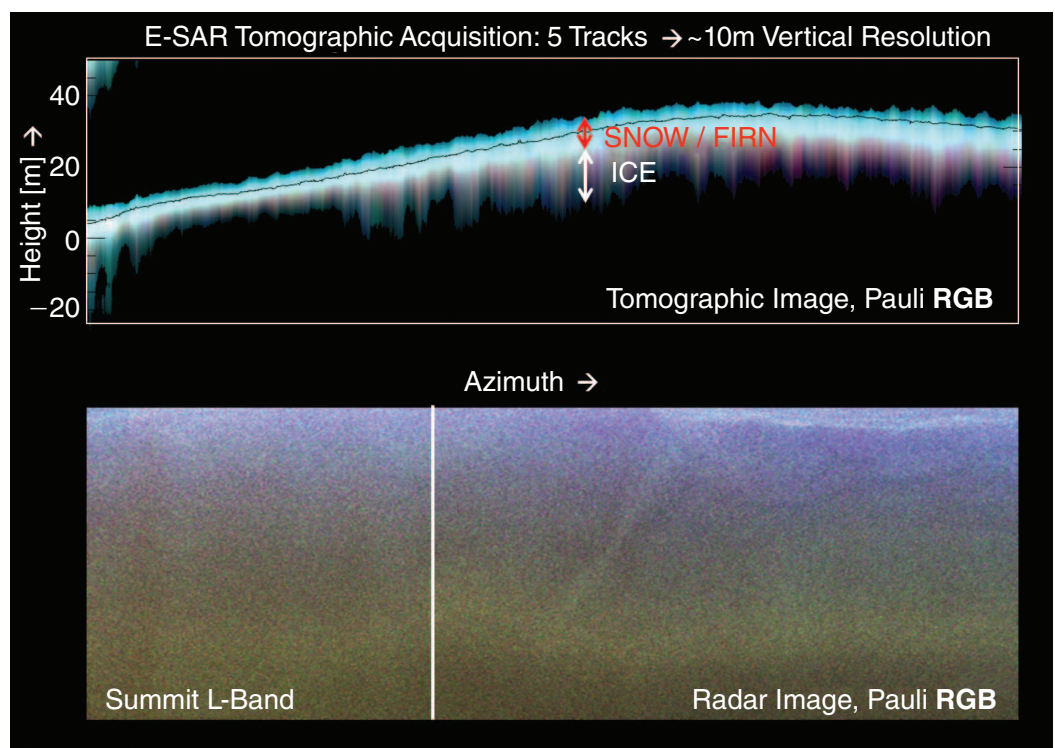

FIGURE 5. Top: Tomographic image, Pauli-RGB (Red: HH-VV, Blue: HH+VV, Green: $\mathrm{HV}+\mathrm{VH})$ : Representation of the vertical reflectivity at L-band derived from data acquired by DLR's airborne E-SAR system along a transect of the Austfonna Glacier, in Svalbard, Norway. Bottom: L-band radar image of the test site, Pauli-RGB (Red: HH-VV, Blue: $\mathrm{HH}+\mathrm{VV}$, Green: $\mathrm{HV}+\mathrm{VH})$. The white line indicates the transect shown above.

generation of vertical and horizontal structure information with unprecedented resolution and accuracy. The 3-D structure mode optimally fulfills the requirements of a large number of scientific applications pertaining to the biosphere, hydrosphere and cryosphere. The basis of the 3-D structure mode is the combination of polarimetric SAR interferometry (Pol-InSAR) with multiple baseline SAR coherence tomography [29], [30], [31]. 


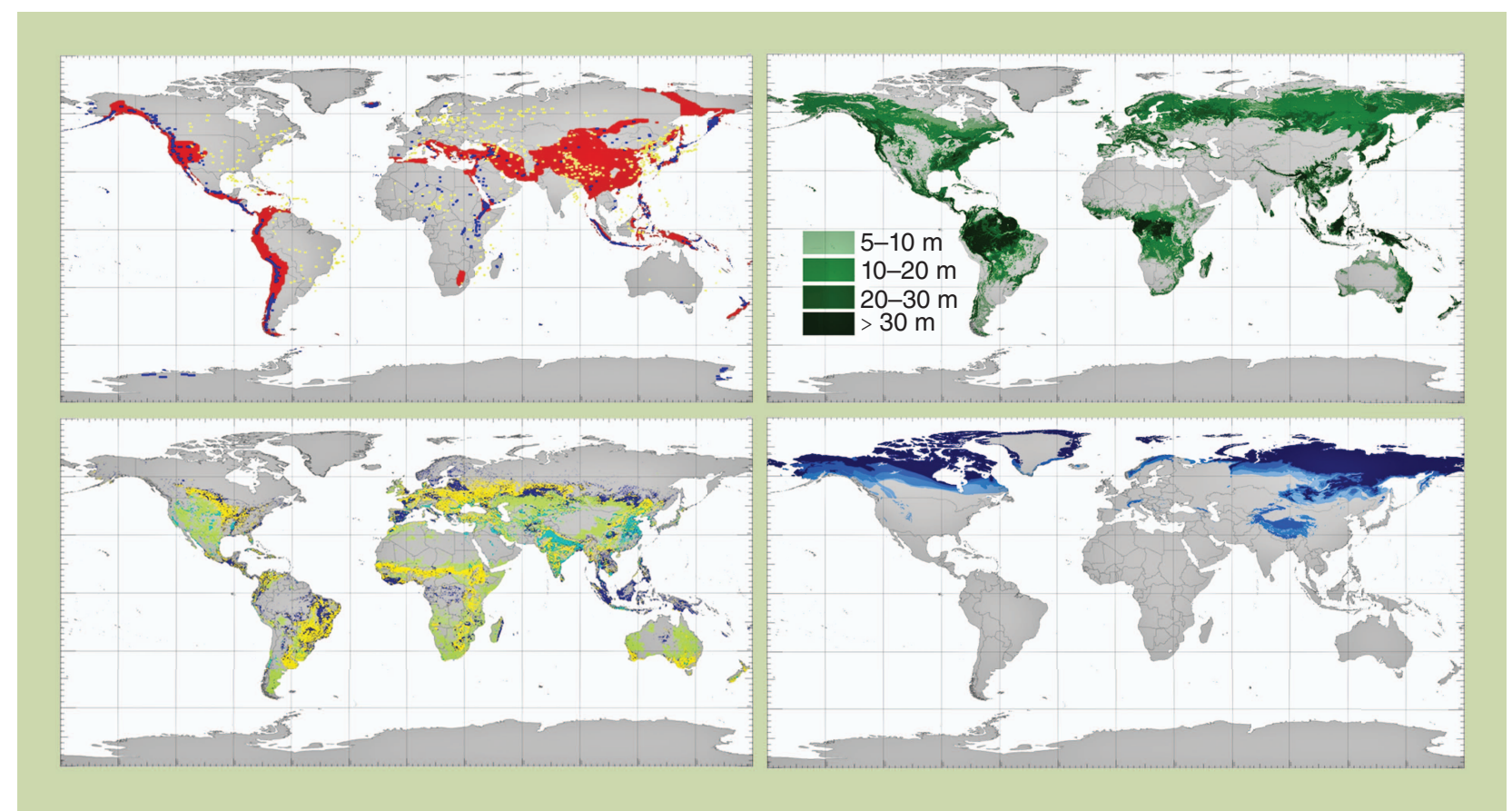

FIGURE 6. Upper Left: Tectonic active regions (combination of UNAVCO's Global Strain Map, World Gazetteer cities and Volcanos from Smithsonian Global Volcanism Program); Upper Right: Forest height map (based on FAO and lidar data); Lower Left: Agricultural maintained land (based on FAO); Lower Right: Permafrost regions (GLIMS).

Tandem- $L$ will be the first radar mission that can provide recurrent 3-D structure measurements with high spatial and temporal resolution on a global scale. The repeated tomographic observations will provide a unique data base for the scientific monitoring of internal structure dynamics in vegetation, soil and ice. A further important application is the simultaneous generation of both a digital surface and a digital terrain model, thereby complementing and updating the digital elevation data acquired by TanDEM-X [32], [33].

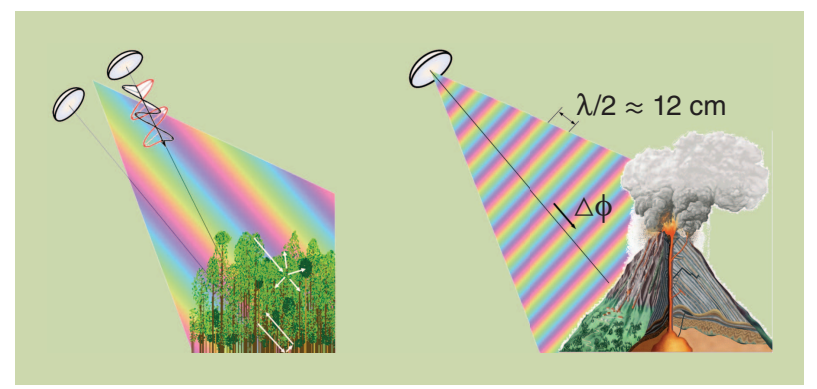

FIGURE 7. Two basic measurement modes of Tandem-L. Left: The 3-D structure mode employs polarimetric SAR interferometry and coherence tomography to measure tree heights and vertical vegetation profiles. The individual contributions from ground and canopy can be separated via their polarimetric signatures and the corresponding heights can be measured by cross-track interferometry and multi-baseline tomography. Right: The deformation mode employs repeat-pass interferometry to measure range displacements with millimetric accuracy.
D The deformation mode employs repeat-pass interferometry to systematically monitor small and large-scale shifts on the Earth's surface with accuracies down to centimeters or even millimeters (Figure 7, right). An innovative ultra-wide swath SAR imaging mode with $350 \mathrm{~km}$ cross-track coverage and a hitherto unparalleled azimuth resolution of 7-10 $\mathrm{m}$ will support the generation of consistent image stacks for large contiguous areas with frequent updates. This provides a solid data base to mitigate temporal decorrelation as well as tropospheric and ionospheric propagation errors. 3-D motion vectors are derived by combining data acquired from ascending and descending orbits with different incident angles as well as in right- and left-looking configurations. Important applications served by the deformation mode are the large-scale monitoring of tectonic shifts at plate boundaries, the regular observation of volcanos, the surveillance of urban subsidence, and systematic surveys of potential landslide areas.

D Additional high-resolution wide-swath SAR modes will provide high quality radar images with a selectable spatial resolution down to $3 \mathrm{~m}$ and a swath width of up to $350 \mathrm{~km}$ in the single- and dual-polarized modes and $175 \mathrm{~km}$ in the quad-polarized mode. Important applications are agricultural and soil moisture mapping, ship routing, as well as ocean, sea ice and ice sheet monitoring. For emergency observations in case of floods, earthquakes, volcanic eruptions, dam or forest damage, etc., the instantaneous access area from a given orbit position can even be increased by performing dedicated roll and 
yaw maneuvers for one satellite. This enables, for most areas on the Earth's surface, the timely acquisition of a SAR image within one or two days. An additional 90 degree rotation of the satellite along its radar line-of-sight axis can moreover be used to acquire fully polarimetric SAR images with an azimuth resolution below $1 \mathrm{~m}$ over a swath width of $50 \mathrm{~km}$.

The innovative imaging modes and techniques of Tandem-L provide the opportunity for unique large-scale measurements with frequent revisits, as required for the global monitoring of dynamic processes on the Earth's surface. Above and beyond the primary mission goals, the data set generated by Tandem-L has immense potential for developing new scientific and commercial applications.

\section{B. SPACE SEGMENT}

For the space segment it is assumed that two identical satellites are developed using a 2-ton class satellite bus. A sunsynchronous orbit with a height of $745 \mathrm{~km}$ and a repeat cycle of 16 days has been selected. This orbit ensures full global coverage in the quad-polarized mode which can provide a swath width of $175 \mathrm{~km}$. Since the single- and dual-polarized modes provide a doubled swath width of $350 \mathrm{~km}$, each point on the Earth can be mapped with at least two incident angles from each, ascending and descending passes. This supports, for example, the derivation of 3-D displacement vectors in the deformation mode. The satellites will be designed for a lifetime of 10 years, with all consumables supporting a mission extension to more than 12 years. Both, bistatic and independent monostatic operation will be adopted in dedicated mission phases [2]. For bistatic measurements, a bidirectional RF link is foreseen that can provide a posteriori (i.e. on ground) a highly accurate mutual time and phase referencing with accuracies in the order of a few picoseconds and a few degrees in L-band, respectively (heritage from TanDEM-X, [32]). The relative position between the satellites will moreover be determined by double differential GPS measurements in two frequency bands. This approach, which already has been used operationally during the TanDEM-X mission, can provide precise estimates of the 3-D baseline vector between the two satellites with accuracies in the order of a few millimeters [32]. Table 1 provides a summary of some key parameters and performance figures of the Tandem-L space segment.

\section{FORMATION FLIGHT}

The Tandem-L acquisition plan foresees a systematic variation of the cross-track base- lines to optimize forest height and vegetation profile measurements in the 3-D structure mode. To provide accurate tree heights and vertical structure profiles in the tropical forests, up to six acquisitions with vertical wavenumbers $k_{z}$ ranging from $0.05 \mathrm{rad} / \mathrm{m}$ up to $0.6 \mathrm{rad} / \mathrm{m}$ are planned for each season. Assuming an orbital altitude of $745 \mathrm{~km}$ and incident angles ranging from $30^{\circ}$ to $40^{\circ}$ in the bistatic quad-pol mode, the required perpendicular baselines vary between $800 \mathrm{~m}$ and $10.7 \mathrm{~km}$. At the equator, this corresponds to horizontal baselines between $1.1 \mathrm{~km}$ and 16.6 $\mathrm{km}$ in case of using a helix formation [32] with no radial orbit separation at zero latitude. An elegant technique to provide this wide range of cross-track baselines exploits the naturally occurring differential secular variations of the right ascension of the ascending nodes in response to slightly different inclinations. Figure 8 illustrates the evolution of the horizontal baselines at the equator for different inclination offsets (expressed as horizontal baselines at the northern and southern orbit turns).

A further challenge for Tandem- $\mathrm{L}$ is the adjustment of large cross-track baselines at higher latitudes for the observation of
TABLE 1. KEY PARAMETERS AND PERFORMANCE FIGURES FOR THE TANDEM-L/ALOS-NEXT SATELLITES.

\begin{tabular}{|c|c|c|}
\hline PARAMETER & VALUE & COMMENTS \\
\hline Orbit height & $745 \mathrm{~km}$ & 231 cycles/16 days \\
\hline Orbital tube & $500 \mathrm{~m}(3 \sigma)$ & Refers to master satellite \\
\hline Horizontal baselines & $1 \mathrm{~km} \mathrm{\ldots ..18} \mathrm{km}$ & $\begin{array}{l}\text { Variable horizontal baselines for bistatic mode } \\
\text { in close formation }\end{array}$ \\
\hline Radial baselines & $0 \mathrm{~m} \ldots 400 \mathrm{~m}$ & $\begin{array}{l}\text { Radial baselines are mainly for passive safety } \\
\text { in close formation (Helix concept) }\end{array}$ \\
\hline Local time & $6 \mathrm{~h} / 18 \mathrm{~h}$ & Dawn/dusk \\
\hline Inclination & $98.4^{\circ}$ & Sun synchronous orbit \\
\hline Revisit time & 16 days & $\begin{array}{l}\text { The } 350 \mathrm{~km} \text { wide swath mode enables up to } 4 \\
\text { global data acquisitions from different viewing } \\
\text { directions every } 16 \text { days }\end{array}$ \\
\hline Frequency & L-band & Available frequency band: $1215 \ldots 1300 \mathrm{MHz}$ \\
\hline Range bandwidth & Up to $85 \mathrm{MHz}$ & $\begin{array}{l}\text { Split frequency modes for ionospheric correc- } \\
\text { tions (for reduced bandwidth modes) }\end{array}$ \\
\hline \multirow[t]{3}{*}{ Azimuth resolution } & $7 \ldots 10 \mathrm{~m}$ & $\begin{array}{l}\text { For swath width up to } 350 \mathrm{~km} \text { (single/dual } \\
\text { pol.), for swath width up to } 175 \mathrm{~km} \text { (quad pol.) }\end{array}$ \\
\hline & $3 \mathrm{~m}$ & $\begin{array}{l}\text { For swath width up to } 175 \mathrm{~km} \text { (quad polariza- } \\
\text { tion), for swath width up to } 350 \mathrm{~km} \text { (single/ } \\
\text { dual pol.) }\end{array}$ \\
\hline & $1 \mathrm{~m}$ & $\begin{array}{l}\text { For } 50 \mathrm{~km} \text { wide swath (all polarizations), swath } \\
\text { access by mechanical steering of satellite }\end{array}$ \\
\hline Downlink capacity & $\sim 8$ terabytes/day & $\begin{array}{l}\text { Based on Ka-band downlink to a ground } \\
\text { station network, extension with X-band and/ } \\
\text { or Laser Communication Terminal (LCT) to be } \\
\text { investigated in phase A }\end{array}$ \\
\hline Look direction & Right \& left & $\begin{array}{l}\text { Nominal: right-looking, } \\
\text { left-looking by horizontal satellite rotation }\end{array}$ \\
\hline Reflector diameter & $15 \mathrm{~m}$ & Deployable reflector with $10 / 15 \mathrm{~m}$ boom \\
\hline Mission lifetime & 10 years & Resources available for at least 12 years \\
\hline Polarization & Single/dual/quad & $\begin{array}{l}\text { Optional use of hybrid and compact pol } \\
\text { modes shall be investigated in conceptual } \\
\text { design/phase-A study }\end{array}$ \\
\hline
\end{tabular}


temperate and boreal forests and the measurement of vertical ice structure in Polar Regions. One opportunity to tackle this challenge is the use of a large eccentricity offset to provide a sufficient radial orbit separation at high latitudes, but a significant $\Delta v$ (amount of fuel) will be required to compensate the resulting motion of libration for longer time periods. A large $\Delta v$ could, for example, be provided by an electric propulsion system. Another opportunity is the use of an even larger separation of the ascending nodes, which may then provide sufficient baselines for accurate forest height retrievals in the mid latitudes. Boreal forests at higher latitudes can moreover be imaged in the alternating bistatic mode which doubles the phase to height scaling, thereby increasing the effective baseline by a factor of two [33].

During specific mission phases, the second satellite can also be used in a constellation mode. For this, one satellite is shifted along its repeat orbit until the same ground track is achieved an integer number of days later. The resulting two-satellite constellation can then effectively shorten the revisit times by a factor of two. This is of great advantage for those applications that require frequent interferometric observations or short average access times. A constellation mode may also be very useful for tailoring the data acquisition in accordance with the needs following earthquakes or other natural disasters.

\section{DATA DOWNLINK, PROCESSING AND ARCHIVING}

The Tandem-L data acquisition not only sets new standards on product quality and availability, but also results in new challenges because of the data volume that has to be transferred to the ground. Current planning foresees that the two Tandem-L satellites will together acquire 8 terabytes of data every day. To transfer this amount of data to the ground the latest transmission technology in Ka-band will be employed together with an international network of ground stations.

To provide users with up-to-date products, on-line processing will be performed keeping in step with the image generation. To limit the processing load, these products may not at first possess the highest possible accuracy, which can often only be achieved in combination with data from other acquisitions and/or auxiliary products. However, they still serve as useful indicators for early warning.

High-quality products will then be delivered to the users on demand. Depending on the type of user these can be sensor-specific products (e.g. SAR images), intermediate products, or even refined geo-information products, such as biomass maps. For a selection of products, users can request specific processing parameters. Product generation and distribution take place via the internet. As far as possible, only intermediate products will be archived. From these, the appropriate final products can be generated as required in accordance with the user needs.

\section{SAR INSTRUMENT}

The Tandem-L science requirements are met through an advanced instrument with capabilities beyond that of any known SAR sensor. Its key feature is the combination of a large deployable reflector antenna with a two-dimensional digital feed array [2]. This allows a flexible beam shaping on transmit for optimum swath illumination. On receive, multiple beams follow the radar echo while it traverses the swath, which can be up to $350 \mathrm{~km}$. For the first time, a spaceborne SAR sensor will utilize beamforming in the digital domain. This is done by quantizing the echo signal received by each antenna element, yielding multiple digital data streams which are filtered (processed) on board the satellite.

The achievable SAR performance described below is orders of magnitude better than that of current SAR systems. In addition, Tandem- $\mathrm{L}$ is capable of full polarimetric operation; by this adding a new dimensionality to conventional SAR performance. The fact that the entire beamforming is done in the digital domain gives access to a huge variety of digital filtering techniques which can be applied utilizing the available hardware. For example, frequency dispersive filters, time varying impulse responses, angular nulling filters, or data compression (pre-summing) may be applied on board. The SAR image generation (processing) is performed on ground using the data of multiple azimuth channels. All of these novel instrument features allow adapting the operation mode and the performance to the scientific requirements.

Mastering the instrument design options and trades is a challenge, not only because of the huge number of inter-dependent parameters. Tandem-L represents an innovative concept for SAR both from the instrument control as well as the mission operation point of view. On the other hand, the (digital) instrument offers all control capabilities necessary for optimization. This represents a quantum leap forward in SAR instrument evolution. 
From an instrument point of view each mode is characterized by the activated elements on transmit, and the selection of the digital data streams which are stored on receive. In addition, radar parameters such as pulse repetition frequency, polarization channels etc. are adapted to the specific mode. The basic modes which are being considered are shown in Table 2.

\section{A. ANTENNA CONCEPT AND OPERATION PRINCIPLE}

The acquisition of very wide swaths with sufficient sensitivity requires large antennas to be deployed into space. Representing the state of the art for communication satellites, large mesh reflectors are recently considered for spaceborne SAR missions. In contrast to direct radiating planar array antennas, a reflector is illuminated by an array of feed elements, which in turn deflects the electromagnetic wave towards the Earth surface. A peculiarity of such array-fed reflector antennas is that each feed element receives echo signals from an essentially non-overlapping angular domain. A 15-m reflector design for Tandem- $\mathrm{L}$ is shown on the left in Figure 9, where the feed array is almost horizontally aligned. A wide swath is illuminated by all elements simultaneously transmitting the chirp signal, as indicated by the broad blue beam. On receive a narrow high gain beam is generated by adopting only a small subset of feed elements in concordance with the direction of the echo signal. By this the receive beam is scanned across the swath from near to far range. This scanning operation, in the
TABLE 2. BASIC MODES OF OPERATION FOR TANDEM-L. VARIATIONS OF THESE IMAGING MODES ARE POSSIBLE, BY ALTERING THE RANGE AND AZIMUTH RESOLUTION, CORRESPONDING TO THE CHIRP AND DOPPLER BANDWIDTH, RESPECTIVELY. FOR THE HIGH-RESOLUTION MODES D1/D2 AND D4 THE OPERATION IN STAGGERED SAR MODE IS BEING INVESTIGATED.

\section{MODE PARAMETERS}

B1/B2 $350 \mathrm{~km}$ swath, $10 \mathrm{~m}$ azimuth, Single/Dual-pol.

B4 $175 \mathrm{~km}$ swath, $10 \mathrm{~m}$ azimuth, Quad-pol.

D1/D2 $350 \mathrm{~km}$ swath, $3 \mathrm{~m}$ azimuth, Single/Dual-pol.

D4 $175 \mathrm{~km}$ swath, $3 \mathrm{~m}$ azimuth, Quad-pol.

\section{DESCRIPTION}

Staggered SAR, linear Tx

Staggered SAR, circular Tx

Stripmap, monostatic image (with gaps), bistatic image (no gaps), linear Tx Stripmap, monostatic image (with gaps), bistatic image (no gaps), circular Tx
SAR literature denoted as SCORE (SCan-On-REceive) [21], [22] can be efficiently implemented by means of digital feed array hardware [24]. Such a concept is presented on the right side of Figure 9. Each of the 36 elevation elements consists of two dual-polarized microstrip patches. On receive the signal is routed through an individual transmit-receive (TR) modules module for horizontal $(\mathrm{H})$ and for vertical (V) polarization and digitized in the corresponding DBF unit. Typically,
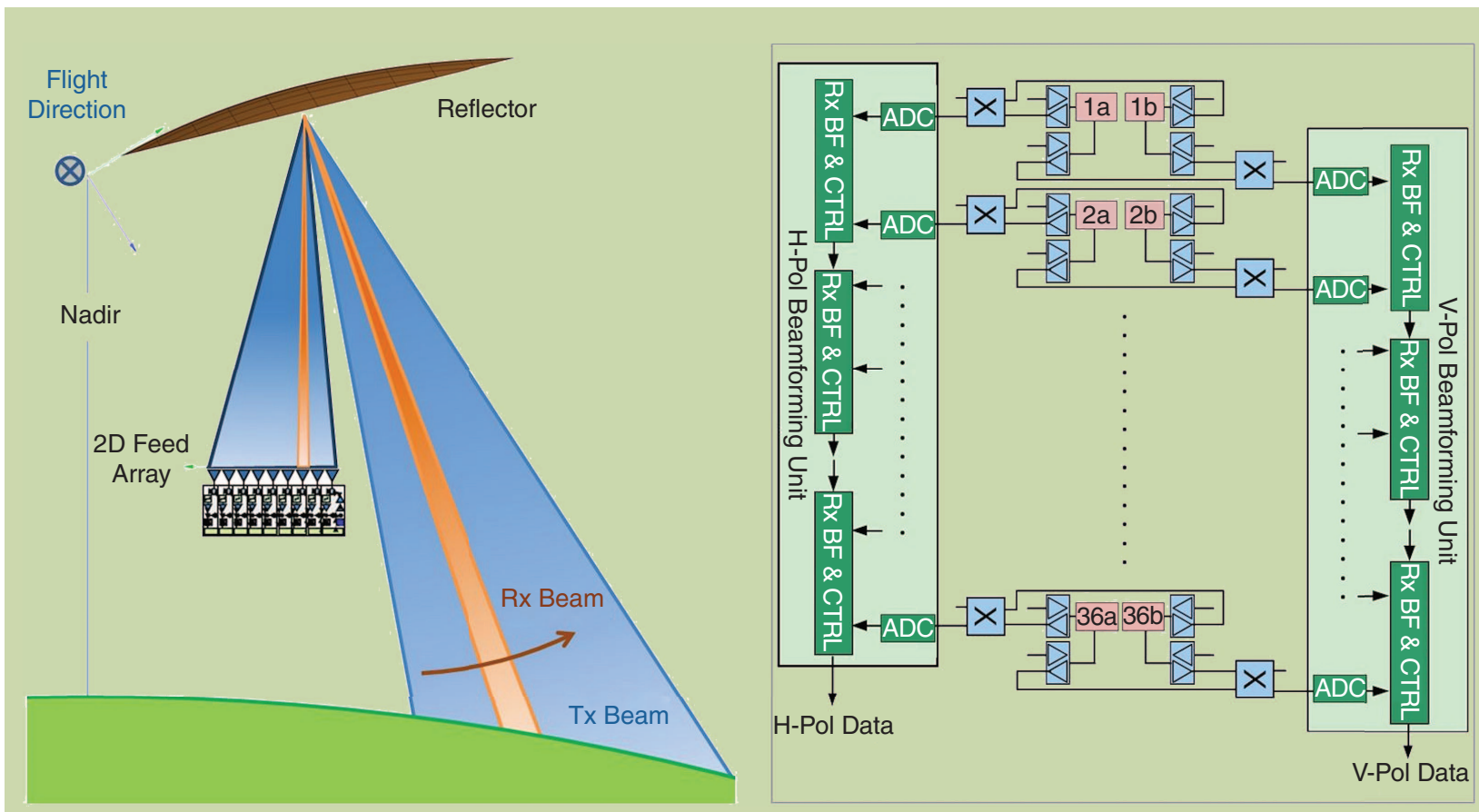

FIGURE 9. Left: Scan-On-Receive operation principle where the entire swath is illuminated with all elevation feed elements active, while on receive a narrow high gain beam follows the pulse on ground. For high azimuth resolution acquisitions the feed array is extended in flight direction by a total of three columns. Right: Receive chain of an individual feed array column, consisting of 36 dual polarized patch pairs (1a...36a, 1b...36b). Each polarization port signal $(\mathrm{H}, \mathrm{V})$ is routed through a transmit-receive (TR) module and digitized in the respective beamforming unit. ADC stands for analog-to-digital converter, Rx for receive, BF for beamforming, CTRL for control. 


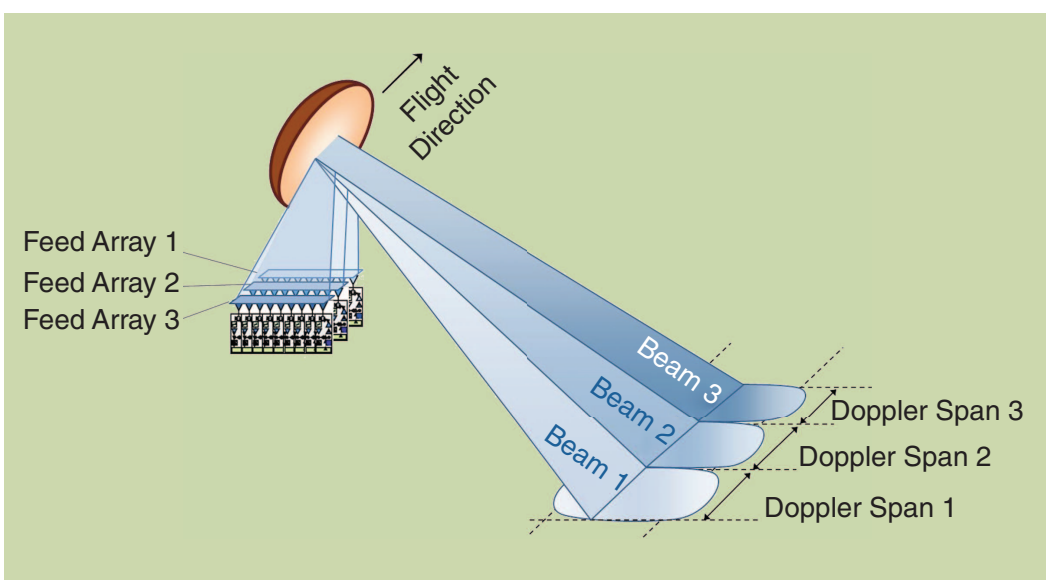

FIGURE 10. Tandem-L reflector and three feed arrays in azimuth required to increase the Doppler spectrum for the fine azimuth resolution mode (3 meter resolution). cover the required Doppler spectrum (see Figure 10). Each column represents an individual azimuth channel to be transferred to ground, where the total Doppler spectrum is recovered by azimuth beamforming techniques [23], [24].

The performance for the 3-m quadpol mode is summarized in Figure 11. In order to cover the swath of $175 \mathrm{~km}$ three elevation beams need to be recorded simultaneously, as can be seen from the timing diagram in the top left. The sensitivity of the system is improved by transmitting circular polarization, effectively doubling the transmit power. This results in a noise equivalent sigma zero (NESZ) better than $-31.5 \mathrm{~dB}$ (top

a beam for a specific direction is generated by combining the output signals of three to seven elevation elements. This combination is performed in FPGA (Field Programmable Gate Arrays) units using complex weights, read from a look-up table.

\section{B. OPERATION AND SAR PERFORMANCE FOR 3-M AZIMUTH RESOLUTION}

This mode is intended to be used for agricultural maps and the emergency mode. Due to the relatively fine azimuth resolution of $3 \mathrm{~m}$ three elevation columns are necessary to right). Without any sophisticated beamforming techniques the azimuth ambiguity-to-signal ratio (AASR) is lower than $-24 \mathrm{~dB}$ (lower left). This might even be improved by nullsteering techniques [23], especially in the center region of the swath. The circular transmit polarization helps to balance the range ambiguity levels. In the lower right of Figure 11 an example for RV polarization (i.e., right polarization on transmit, vertical polarization on receive) is shown. The range ambiguity-to-signal ratio (RASR) in the other three polarization combinations is in the same order or better.

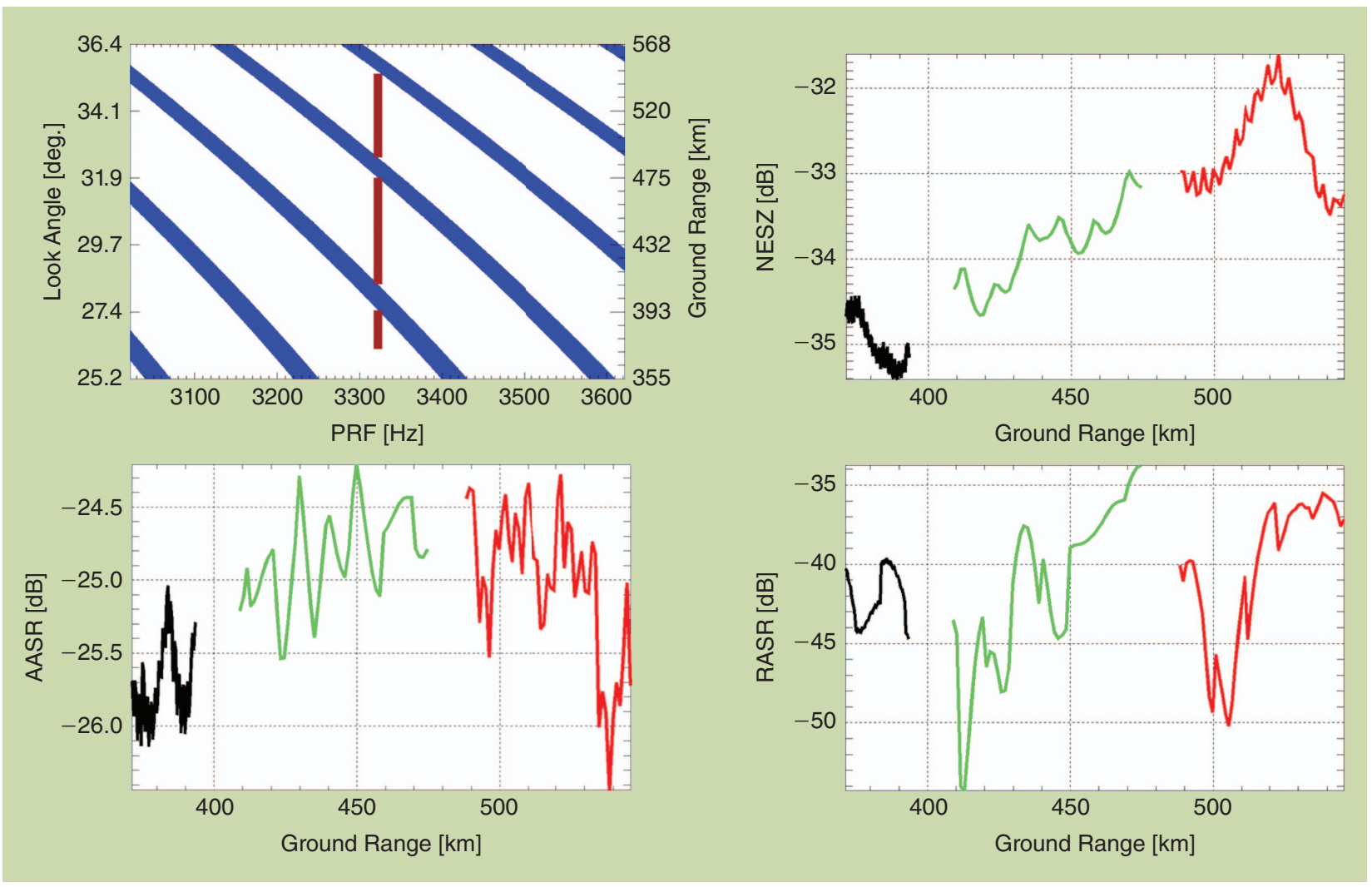

FIGURE 11. SAR performance for the 3-m quad-pol mode (see mode D4 in Table 2). Top left: Timing diagram. Top right: Noise equivalent sigma zero. Lower left: Azimuth ambiguity-to-signal ratio (AASR). Lower right: Range ambiguity-to-signal ratio (RASR). 


\section{STAGGERED SAR OPERATION AND PERFORMANCE}

Staggered SAR is an innovative concept, based on the continuous variation of the pulse repetition interval (PRI) [25], [26]. DBF on receive allows simultaneous imaging of multiple sub-swaths through multiple elevation beams, but "blind ranges" are present between adjacent sub-swaths, as the radar cannot receive, while it is transmitting (left panel of Figure 12) [27]. If the PRI is continuously varied, the position of the blind ranges will be different for each transmitted pulse (right panel of Figure 12). A method has been developed to select the PRIs of the sequence such that two consecutive samples in the azimuth direction are never missed [25]. In this way, if the signal is averagely oversampled in azimuth, it is possible to accurately interpolate the data on a uniform grid and obtain a high resolution SAR image over a wide continuous swath. The oversampling in azimuth determines an increase of the data volume to be downlinked, which can, however, be significantly reduced by filtering and decimating the data on-board [28]. If such sequences of PRIs are used, and data are resampled using best linear unbiased (BLU) interpolation, it can be shown that the aforementioned system is able to image a $350 \mathrm{~km}$ continuous swath with noise equivalent sigma zero and ambiguity performance shown in Figure 13.

\section{OBSERVATION CONCEPT}

Tandem-L combines unprecedented imaging capabilities with equally ambitious observation requirements. This section provides an outline of how the different science objectives can be optimally served with the mission. The overall mission concept includes two alternating phases: a bistatic phase with both spacecraft flying in close formation in order to allow single-pass interferometric acquisitions, and a monostatic phase, with both spacecraft flying independently in order to halve the revisit time. This section will focus on the bistatic phase, since it is the most challenging from a mission design point of view.

Aside from the nominal imaging capabilities of the SAR system, the observation concept is mainly constrained by the scarcity of two resources:

1) The total available delta-v budget, or, in physical terms, the amount of propellant available for maneuvers. This sets a constraint on what is possible in terms of formation flying and, consequently, the temporal evolution of the cross-track baseline (or, equivalently, the vertical wavenumber, $k_{z}$ ). For example, large vertical baselines, achieved through a relative eccentricity vector, would imply costly maneuvers to maintain the relative argument of perigee.

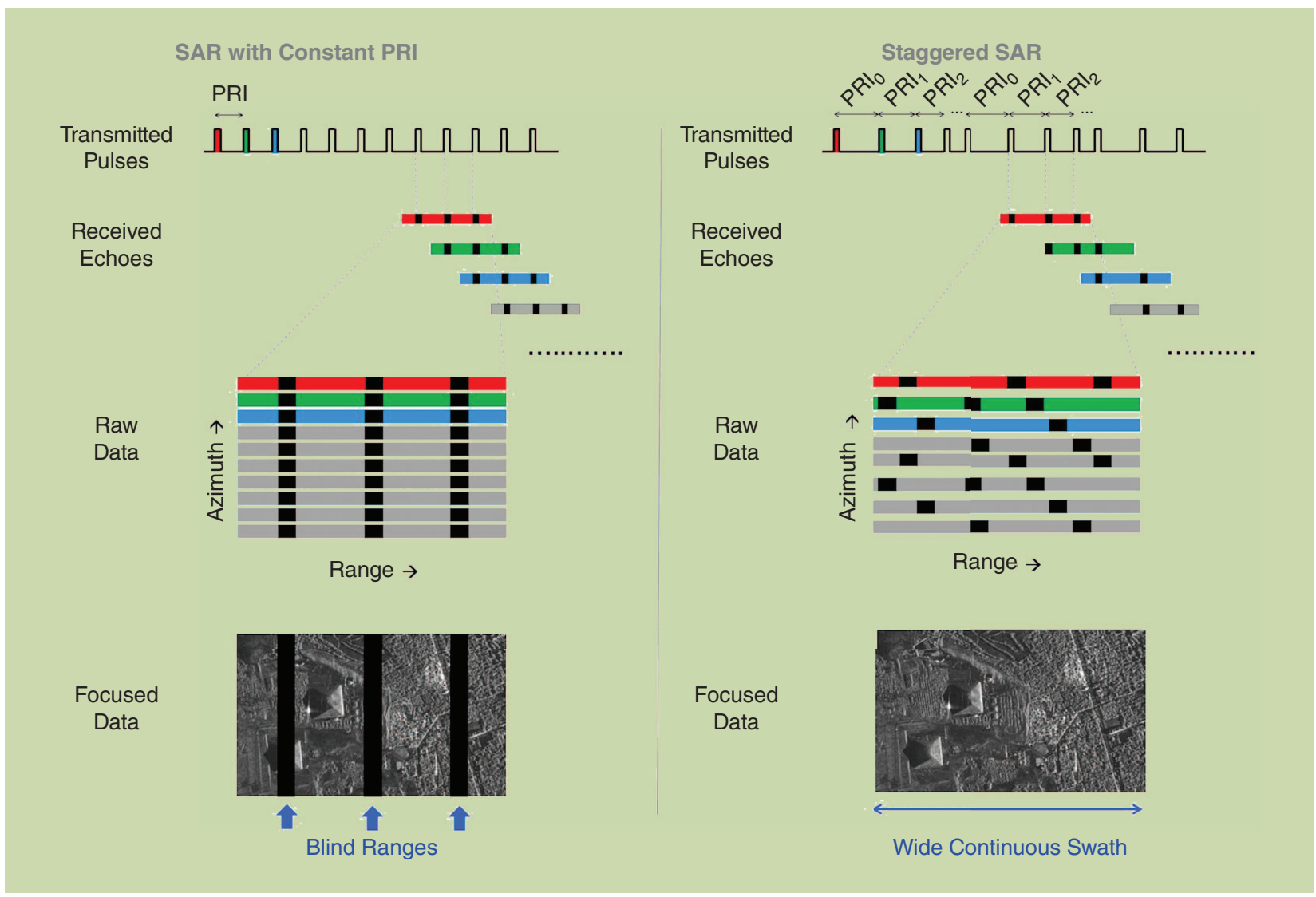

FIGURE 12. Top: Transmitted pulses and corresponding received echoes (same colors as the transmitted pulses) with blind ranges (samples in black, where the echo cannot be recorded, as the radar is transmitting). Middle: Raw data obtained by arranging side by side the received echoes. Bottom: Focused data for a SAR with constant Pulse Repetition Interval - PRI (left) and for a staggered SAR (right). 


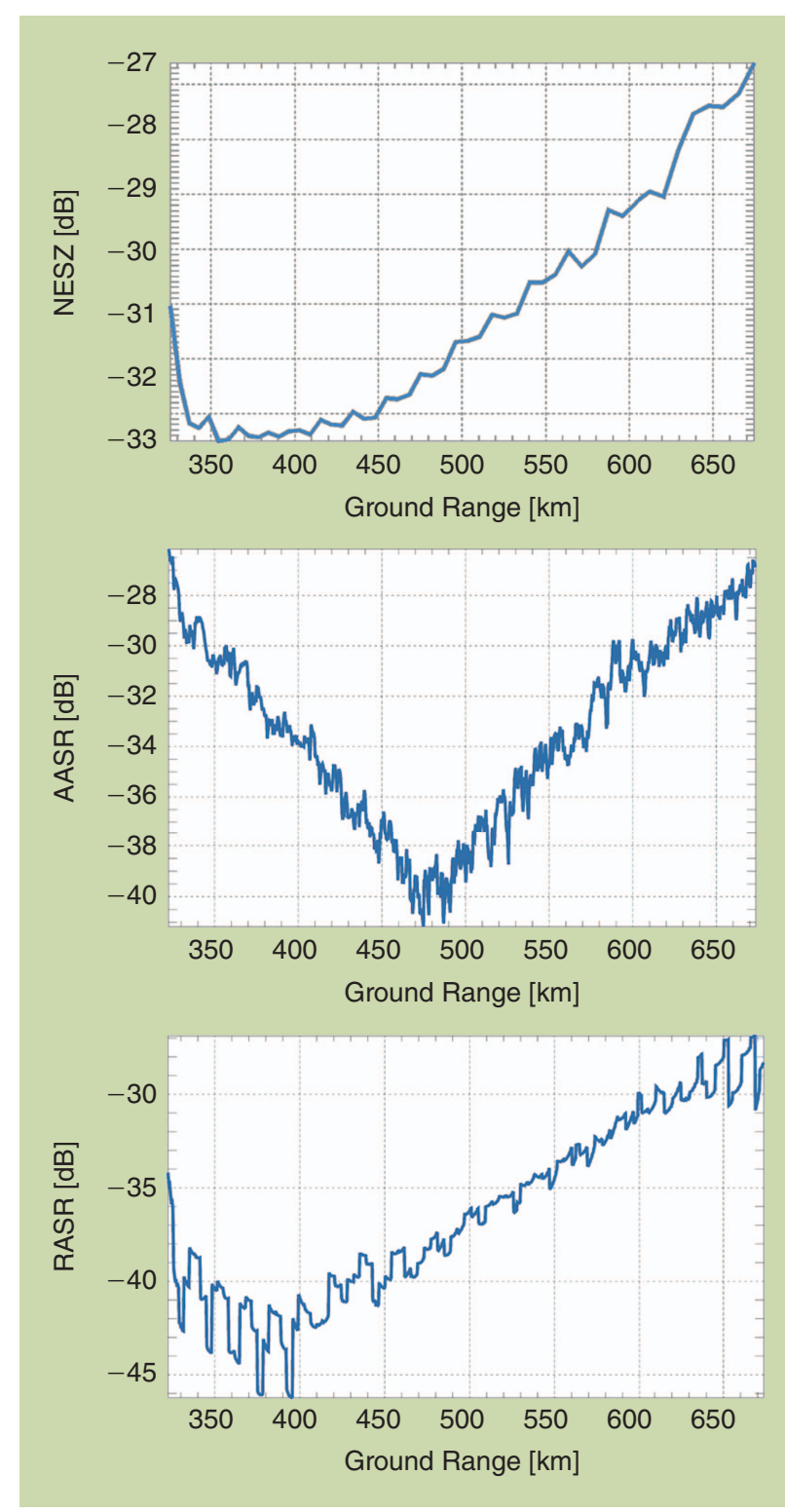

FIGURE 13. Noise equivalent sigma zero (NESZ), azimuth ambiguity-to-signal ratio (AASR) and range ambiguity-to-signal ratio (RASR) for the B1/B2 imaging modes (cf. Table 2) of Tandem-L.

2) The data volume that can be transferred to ground in a given time period (typically expressed in terms of daily down-link capability). Under full exploitation of its multiple receive channels, Tandem- $\mathrm{L}$ can produce data at rates that exceed the feasible down-link capacity in the foreseeable future.

As discussed in Section III, the temporal evolution of the vertical wavenumber is achieved by slightly varying the inclination of one of the spacecraft. Rather than a linear variation of the baseline, the retrieval of forest structure requires a given combination of smaller and larger values $k_{z}$. To achieve the required profile, a bistatic phase would start with a small delta-inclination $(\Delta i)$, resulting in a slow growth of the horizontal baseline at the Equator, which would be accelerated by successive increases of $\Delta i$ during

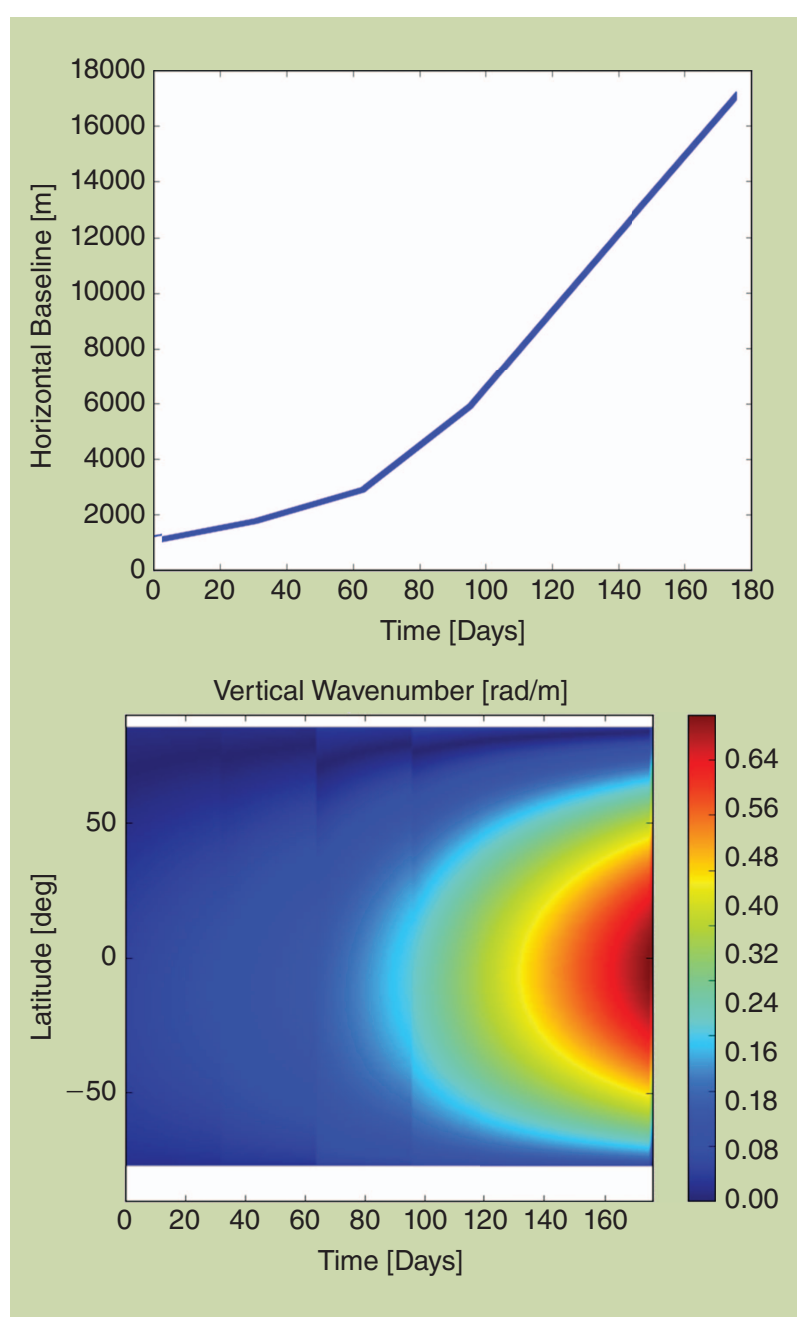

FIGURE 14. Left: evolution of horizontal separation (baseline) at equator during a bistatic cycle. Right: vertical wavenumber as function of time and latitude for ascending tracks (incidence angle: $36^{\circ}$ ).

a bistatic phase. This is illustrated in the left panel of Figure 14, which shows the evolution of the Equatorial horizontal separation during a 176-day bistatic cycle. The right panel in the figure shows the resulting vertical wavenumber as a function of time and latitude and for ascending passes. The North-South asymmetry is caused, mainly, by the rightlooking geometry. It should be noted that the proposed mechanism to control the baseline evolution, fails to provide adequate vertical wavenumbers at very high latitudes, for which a complementary approach may be needed.

The primary way to limit the data volume is by carefully analyzing the observation requirements and translating them into the minimum mode (in terms of data rate) needed to meet them. Once this is done, an observation scenario has to be crafted that fulfills the scientific requirements while addressing potential conflicts between applications and considering the mission constraints. Since forest structure acquisitions are tied to the occurrence of particular vertical wavenumbers at the latitudes of interest, they have to be inserted first in the timeline. Forest acquisitions require 3 to 
5 acquisitions per bistatic cycle. This can be obtained scheduling acquisitions every other cycle (32 days) or, every three cycles (48 days). The acquisitions are grouped by latitude, reflecting the latitude dependence of the effective baselines. Forest and other acquisitions requiring quad-pol modes use a $175 \mathrm{~km}$ swath mode, while applications requiring only single or dual-pol acquisitions benefit from wider, $350 \mathrm{~km}$, swath modes. This doubles the number of potential acquisitions and, consequently, relaxes the scheduling.

Table 3 provides a very high level and simplified overview of the basic observation scenario foreseen during a bistatic phase. Here, different applications have been grouped, exploiting observation synergies between them. For example, forest acquisitions are partially covered by the acquisitions required to provide the global reference maps. The table also hints at the acquisition timeline optimization that can be achieved by distributing the observation requirements between ascending and descending passes. Figure 15 shows how this scheduling translates into daily duty-cycles, segregated by operating modes. The baseline timeline drives the number of bistatic quad-pol (B4) acquisitions, while seasons can be recognized in the acquisition timeline for agriculture related (monostatic B4) and ice related modes. In contrast, modes associated to the geosphere (deformations) show an almost constant profile (with variations obeying to acquisition conflicts).

\section{CONCLUSIONS AND OUTLOOK}

This paper provides an overview of the Tandem-L mission including the science requirements, mission concept, observation scenario and instrument design. Beside the scientific component, the distinguishing feature of Tandem- $\mathrm{L}$ is the high degree of innovation with respect to the methodology and technology. Examples are polarimetric SAR interferometry for measuring forest height, multiple-pass coherence tomography for determining the vertical structure of vegetation and ice, utilization of the latest beamforming techniques for increasing the swath width and imaging resolution and close formation flying of two cooperative radar satellites with adjustable spacing. Tandem-L is characterized by three major innovations:

Dystematic global data acquisition with unprecedented spatial and temporal resolution using novel SAR imaging modes

D formation flight of two radar satellites with variable cross-track baselines for single-pass interferometry and tomography

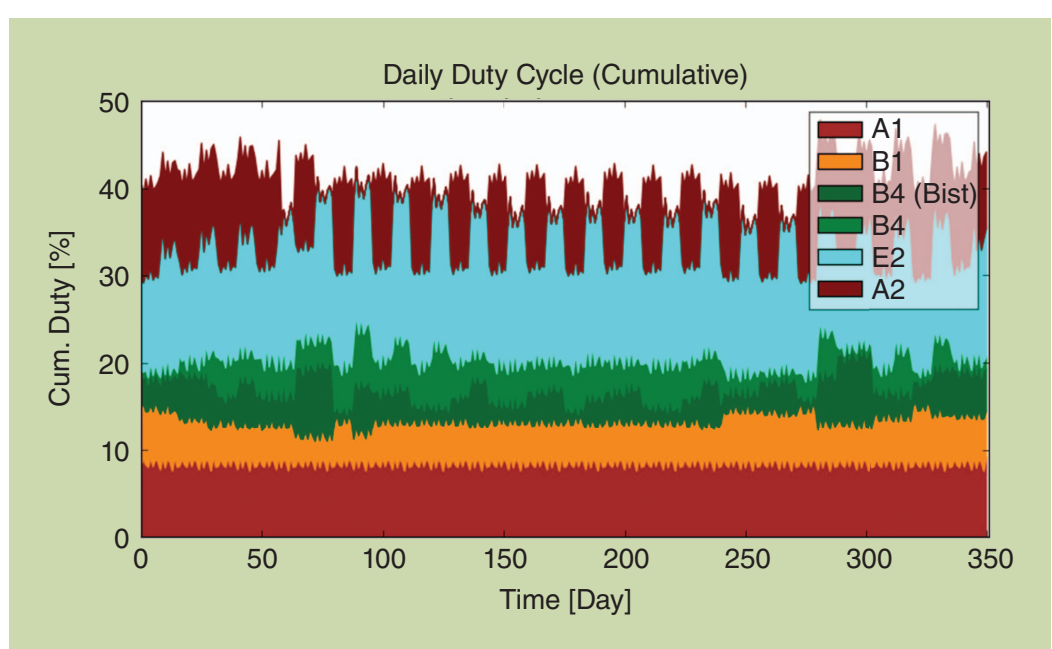

FIGURE 15. Daily duty cycles segregated by observation mode during one year of bistatic observations. Imaging modes B1 and B4 are described in Table 2. Imaging modes $\mathrm{Al} / \mathrm{A} 2$ are similar to $\mathrm{B1} / \mathrm{B} 2$, but with $20+5 \mathrm{MHz}$ split bandwidth. Mode E2 is a dual-pol imaging mode with $20 \mathrm{MHz}$ bandwidth and $50 \mathrm{~m}$ azimuth resolution. 


\section{TABLE 4. UNIQUENESS OF TANDEM-L PRODUCTS AND APPLICATIONS.}

\section{PRODUCT}

TANDEM-L

3-D Forest Height High spatial and vertical resolution

\& Structure

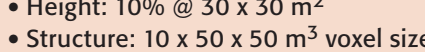

Drequent monitoring for the assess-

ment of seasonal and annual dynamics (2 global coverages/year)

\section{Digital Elevation} Model

3-D Deformation

accuracy and resolution

- Seasonal and yearly updates

High resolution deformation maps on a global scale

- Systematic acquisition concept for the measurement of 3-D vector movements

- Low temporal decorrelation in L-band
3-D Ice Structure High spatial and vertical resolution - Monitoring of seasonal and annual dynamics

Soil Moisture
Digh spatial resolution $\left(30 \times 30 \mathrm{~m}^{2}\right)$

D (Bi-)weekly acquisitions

\section{AVAILABLE PRODUCTS (CURRENT, APPROVED OR PLANNED MISSIONS)}

- BIOMASS (approved):

- Lower vertical and horizontal resolution (voxel size worse by a factor of 40)

- No global coverage (SOTR restrictions in Europe, North America and parts of Asia)

- No structure dynamics (single tomographic measurement dispersed over one year)

D GEDI (approved)

- No seamless coverage (only lidar tracks)

- No global coverage (lack of northern boreal forests)

- poor performance for the assessment of seasonal and annual dynamics

- SAOCOM-CS (planned):

- Mostly demonstration with reduced performance

- No global coverage and no dynamics

D TanDEM-X (current):

- Provides only a digital surface model

- No updates

Dentinel-1 (current):

- Increased susceptibility to temporal decorrelation due to four times shorter wavelength in C-band

- Lower spatial resolution in TOPS mode

- No dedicated acquisition plan and processing for 3-D vector movements

ALOS-2 (current):

- No systematic acquisition for large-scale deformations and no processing of image stacks

- Conventional SAR with limited swath width and/or resolution

D TerraSAR-X/TanDEM-X (current):

- Can only acquire one global acquisition/year

- Strong temporal decorrelation in X-band

D No comparable spaceborne data available yet (currently only small-scale airborne and ground-based sounder/GPR data available).

- Spaceborne radiometers and scatterometers (SMOS, SMAP, ...) provide only resolutions in the order of $10 \mathrm{~km}$ and more

- SAOCOM (approved) is a conventional SAR with significantly worse spatial and temporal resolution

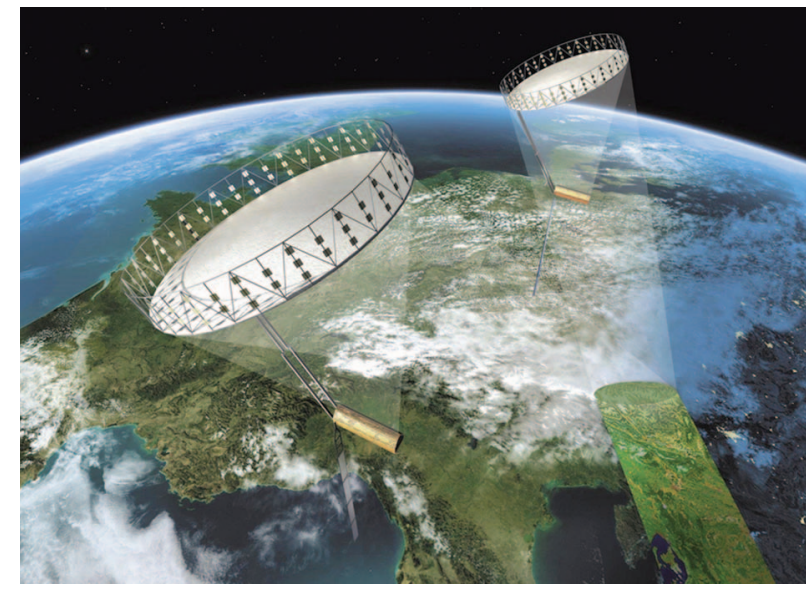

FIGURE 16. Artist's view of Tandem-L in a bistatic formation flight.

Presently, Tandem- $\mathrm{L}$ is undergoing a phase A study by DLR. Figure 16 shows the artist's view of the satellite design under investigation by the German space industries. The goal is a launch by 2021. Due to the innovations in science, methodology and technology, Tandem- $\mathrm{L}$ is predestined to lay the foundation for future SAR missions towards a unique spaceborne Earth observatory for continuous monitoring of the Earth and its environment, analogous to the existing network of weather satellites. Further studies include the investigation of a Tandem-L-based mission concept for daily monitoring of geo/bio-environmental phenomena as well as tectonic hazards prevalent within the inner tropical belt by means of equator-orbiting satellites [34], [35].

\section{ACKNOWLEDGMENT}

The authors would like to thank the JAXA team who jointly worked with the DLR team during the pre-phase-A study as well as the science team of the HGF Alliance HA-310 "Remote Sensing and Earth System Dynamics" for their valuable and extensive contribution to the definition of the science requirements of the Tandem-L mission.

\section{REFERENCES}

[1] A. Moreira, G. Krieger, I. Hajnsek, K. Papathanassiou, M. Younis, F. Lopez-Dekker, S. Huber, M. Eineder, M. Shimada, T. Motohka, M. Watanabe, M. Ohki, A. Uematsu, and S. Ozawa, "TandemL/ALOS-Next: A highly innovative SAR mission for global observation of dynamic processes on the Earth's surface," in Proc. IGARSS, Milan, Italy, July 2015. 
[2] G. Krieger, I. Hajnsek, K. Papathanassiou, M. Shimada, M. Watanabe, M. Younis, F. Lopez-Dekker, Y. Chishiki, F. de Zan, E. Diedrich, M. Eineder, S. Huber, C. Minet, A. Moreira, T. Motohka, M. Ohki, S. Ozawa, M. Pardini, A. Parizzi, A. Rosenqvist, Y. Sudo, A. Uematsu, T. Yahata, S. Yamakawa, T. Yamamoto, R. Yoshino, M. Bachmann, and B. Grafmüller, "Tandem-L/ALOS-Next: A satellite mission for systematic monitoring of the Earth's surface and its dynamics," DLR/JAXA Pre-Phase-A Report, July 2014, p. 183.

[3] I. Hajnsek, M. Shimada, M. Eineder, K. Papathanassiou, T. Motohka, M. Watanabe, M. Ohki, F. de Zan, F. Lopez-Dekker, G. Krieger, and A. Moreira, "Tandem-L: Science requirements and mission concept," in Proc. European Conf. Synthetic Aperture Radar, Berlin, Germany, June 2014, pp. 1-4.

[4] S. Ozawa, "Design concept of large deployable reflector for next generation L-band SAR satellite," in Proc. 2nd Int. Scientific Conf. Advanced Lightweight Structures Reflector Antennas, Tbilisi, Georgia, Oct. 2014, pp. 43-51.

[5] G. Krieger, I. Hajnsek, K. Papathanassiou, M. Younis, and A. Moreira, "Interferometric synthetic aperture radar (SAR) missions employing formation flying," Proc. IEEE, vol. 98, no. 5, pp. 816-843, 2010.

[6] M. Shimada, "JAXA earth observation programs digest," IEEE Geosci. Remote Sensing Mag., vol. 2, no. 2, pp. 47-52, 2014.

[7] A. Moreira, P. Prats-Iraola, M. Younis, G. Krieger, I. Hajnsek, and K. Papathanassiou, "A tutorial on synthetic aperture radar," IEEE Geosci. Remote Sensing Mag., vol. 1, no. 1, pp. 6-43, Mar. 2013.

[8] A. Ferretti, C. Prati, and F. Rocca, "Permanent scatterers in SAR interferometry," IEEE Trans. Geosci. Remote Sensing, vol. 39, no. 1, pp. 8-20, 2001.

[9] P. Lundgren, F. Casu, M. Manzo, A. Pepe, P. Berardino, E. Sansosti, and R. Lanari, "Gravity and magma spreading of Mount Etna volcano revealed by radar interferometry," Geophys. Res. Lett., Feb. 2004

[10] T. R. Walter and F. Amelung, "Volcano-earthquake interaction at Mauna Loa Volcano, Hawaii," J. Geophys. Res., vol. 111, May 2006.

[11] J. T. Salzer, M. Nikkhoo, T. R. Walter, H. Sudhaus, G. Reyes-Dávila, M. Bretón, and R. Arámbula, "Satellite radar data reveal shortterm pre-explosive displacements and a complex conduit system at Volcán de Colima, Mexico," Front. Earth Sci., vol. 2, no. 12, 2014.

[12] R. A. Houghton, F. Hall, and S. J. Goetz, "Importance of biomass in the global carbon cycle," J. Geophys. Res., vol. 114, G00E03, 2009.

[13] R. A. Houghton, "Tropical deforestation as a source of greenhouse gas emissions," in Tropical deforestation and climate change, (IPAM-Instituto de Pesquisa Ambiental da Amazônia, Environmental Defense). P. Moutinho and S. Schwartzman, Eds. Washington, DC, 2005

[14] F. G. Hall, K. Bergen, J. B. Blair, R. Dubayah, R. G. Houghton, G. Hurtt, J. Kellndorfer, M. Lefsky, J. Ranson, S. Saatchi, H. H. Shugart, and D. Wickland, "Characterizing 3D vegetation sructure from space: Mission requirements," Remote Sensing Environ., vol. 115, no. 11, pp. 2753-2775, 2011.

[15] D. A. Robinson, C. S. Campbell, J. W. Hopmans, B. K. Hornbuckle, S. B. Jones, O. F. Knight, J. Selker, and O. Wendroth, "Soil moisture measurement for ecological reasons and hydrological watershed-scale observatories. A review, “ Vadose Zone J., vol. 7, pp. 358-389, 2008.

[16] E. F. Wood, "Why the hydrological community needs hyper-resolution land surface modelling: A grand challenge for the community," in Proc. ESSS, Japan, 2010.

[17] C. Montzka, H. R. Bogena, L. Weihermüller, F. Jonard, C. Bouzinac, J. Kainulainen, J. Balling, A. Loew, J. DallAmico, E. Rouhe, J. Vanderborght, and H. Vereecken, "Brightness temperature validation at different scales during the SMOS validation campaign in the Rur and Erft catchments, Germany," IEEE Trans. Geosci. Remote Sensing, vol. 51, no. 3, Mar. 2013.

[18] T. F. Stocker, D. Qin, G.-K. Plattner, M. Tignor, S. K. Allen, J. Boschung, A. Nauels, Y. Xia, V. Bex, and P. M. Midgley, Eds. "Climate change 2013: The physical science basis," in Contribution of Working Group I to the Fifth Assessment Report of the Intergovernmental
Panel on Climate Change. Cambridge, U.K.: Cambridge Univ. Press, 2013, pp. 15-35.

[19] P. Lemke, J. Ren, R. B. Alley, I. Allison, J. Carrasco, G. Flato, Y. Fujii, G. Kaser, P. Mote, R. H. Thomas, and T. Zhang, "Observations: Changes in snow, ice and frozen ground, in climate change 2007: The physical science basis," in Contribution of Working Group I to the Fourth Assessment Report of the Intergovernmental Panel on Climate Change. Cambridge, U.K.: Cambridge Univ. Press, 2007, pp. 337-383.

[20] S. Rahmstorf, "A new view on sea level rise," Nature Reports Climate Change, Apr. 2010.

[21] J. T. Kare, "Moving receive beam method and apparatus for synthetic aperture radar," U.S. Patent 6175326 B1, Jan. 16, 2001.

[22] G. Krieger, M. Younis, N. Gebert, S. Huber, F. Bordoni, A. Patyuchenko, and A. Moreira, "Advanced digital beamforming concepts for future SAR systems," in Proc. IEEE Int. Geoscience Remote Sensing Symp., July 2010, pp. 245-248.

[23] S. Huber, M. Younis, A. Patyuchenko, G. Krieger, and A. Moreira, "Spaceborne reflector SAR systems with digital beamforming," IEEE Trans. Aerospace Electron. Syst., vol. 48, no. 4, pp. 3473-3493, Oct. 2012.

[24] M. Younis, S. Huber, F. Lopez-Dekker, and G. Krieger, "Instrument design and performance for an L-Band reflector-based SAR mission," in Proc. 4th ESA Workshop Advanced RF Sensors Remote Sensing Instruments and Ka-Band Earth Observation Radar Missions Workshop, Noordwijk, The Netherlands, Nov. 2014.

[25] M. Villano, G. Krieger, and A. Moreira, "Staggered SAR: High resolution wide-swath imaging by continuous PRI variation," IEEE Trans. Geosci. Remote Sensing, vol. 52, no. 7, pp. 4462-4479, July 2014.

[26] M. Villano, G. Krieger, and A. Moreira, "A novel processing strategy for staggered SAR," IEEE Geosci. Remote Sensing Lett., vol. 11, no. 11, pp. 1891-1895, Nov. 2014.

[27] G. Krieger, N. Gebert, M. Younis, F. Bordoni, A. Patyuchenko, and A. Moreira, "Advanced concepts for ultra-wide-swath SAR imaging," in Proc. European Conf. Synthetic Aperture Radar, Friedrichshafen, Germany, 2008, pp. 1-4.

[28] M. Villano, G. Krieger, and V. del Zoppo, "On-board Doppler filtering for data volume reduction in spaceborne SAR systems," in Proc. Int. Radar Symp., Gdansk, Poland, 2014, pp. 1-6.

[29] K. Papathanassiou and S. Cloude, "Single-baseline polarimetric SAR interferometry," IEEE Trans. Geosci. Remote Sensing, vol. 39, no. 11, pp. 2352-2363, 2001.

[30] S. Cloude, "Polarization coherence tomography," Radio Sci., vol. 41, RS4017, 2006.

[31] I. Hajnsek, F. Kugler, S. Lee, and K. Papathanassiou, "Tropicalforest-parameter estimation by means of Pol-InSAR: The INDREX-II campaign," IEEE Trans. Geosci. Remote Sensing, vol. 47, no. 2, pp. 481-493, 2009.

[32] G. Krieger, M. Zink, M. Bachmann, B. Bräutigam, D. Schulze, M. Martone, P. Rizzoli, U. Steinbrecher, J. W. Antony, F. de Zan, I. Hajnsek, K. Papathanassiou, F. Kugler, M. R. Cassola, M. Younis, S. Baumgartner, F. Lopez-Dekker, P. Prats, and A. Moreira, "TanDEM-X: A radar interferometer with two formation-flying satellites," Acta Astronautica, vol. 89, pp. 83-98, 2013.

[33] G. Krieger, A. Moreira, H. Fiedler, I. Hajnsek, M. Werner, M. Younis, and M. Zink, "TanDEM-X: A satellite formation for high-resolution SAR interferometry," IEEE Trans. Geosci. Remote Sensing, vol. 45, no. 11, pp. 3317-3341, 2007.

[34] W.-M. Boerner, "Multi-band equatorially orbiting wide-swath high resolution POLSAR satellite sensors for varying latitudinal belt coverage," in Proc. IGARSS, Milan, Italy, July 2015.

[35] W.-M. Boerner, et al. "Development of new multi-band equatorially orbiting POLinSAR satellite sensors system configurations for varying latitudinal coverage within the tropical belt," in Proc. APSAR conf., Singapore, Sept. 2015.

[36] M. Bertoluzza, J. S. Kim, M. Pardini, L. Bruzzone, and K. Papathanassiou, "On the potentials of POLinSAR inversion for monitoring long-term forest height dynamics at L-band," in Proc. ESA POLinSAR Workshop, Frascati, Italy, Jan. 2015. 